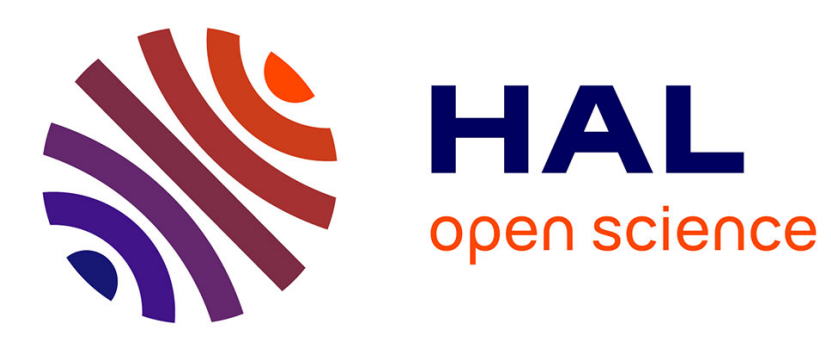

\title{
Cuticular hydrocarbons distinguish cryptic sibling species in Euglossa orchid bees
}

\author{
Tamara Pokorny, Klaus Lunau, J. Quezada-Euan, Thomas Eltz
}

\section{To cite this version:}

Tamara Pokorny, Klaus Lunau, J. Quezada-Euan, Thomas Eltz. Cuticular hydrocarbons distinguish cryptic sibling species in Euglossa orchid bees. Apidologie, 2014, 45 (2), pp.276-283. 10.1007/s13592013-0250-5 . hal-01234729

\section{HAL Id: hal-01234729 \\ https://hal.science/hal-01234729}

Submitted on 27 Nov 2015

HAL is a multi-disciplinary open access archive for the deposit and dissemination of scientific research documents, whether they are published or not. The documents may come from teaching and research institutions in France or abroad, or from public or private research centers.
L'archive ouverte pluridisciplinaire HAL, est destinée au dépôt et à la diffusion de documents scientifiques de niveau recherche, publiés ou non, émanant des établissements d'enseignement et de recherche français ou étrangers, des laboratoires publics ou privés. 


\title{
Cuticular hydrocarbons distinguish cryptic sibling species in Euglossa orchid bees
}

\author{
Tamara PoKorny ${ }^{1,2}$, Klaus Lunau ${ }^{2}$, J. Javier G. QueZadA-Euan ${ }^{3}$, Thomas Eltz ${ }^{1}$ \\ ${ }^{1}$ Department of Animal Ecology, Evolution and Biodiversity, University of Bochum, 44780 Bochum, Germany \\ ${ }^{2}$ Institute of Sensory Ecology, University of Düsseldorf, 40225 Düsseldorf, Germany \\ ${ }^{3}$ Departamento de Apicultura, Universidad Autónoma de Yucatán, Mérida, Yucatán 97100, Mexico
}

Received 1 July 2013 - Revised 18 September 2013 - Accepted 8 October 2013

\begin{abstract}
Cuticular lipid profiles have been shown to be species specific within many insect genera, allowing a chemotaxonomic classification of individuals. In this study, we analysed the cuticular lipids of the orchid bees Euglossa viridissima Friese and Euglossa dilemma Bembé \& Eltz, cryptic sibling species whose taxonomic status has only recently been clarified. Male individuals of both species were obtained from two locations on the Yucatán Peninsula, Mexico, both in the dry and wet seasons. Their hydrocarbon profiles proved to be species specific, irrespective of location and season. They also allowed a correct assignment of a rare morph of E. viridissima which had long obscured the distinction of the two species. Our results suggest that cuticular hydrocarbon profiles may be suited for chemical taxonomy of orchid bees and might provide an additional clue for difficult species distinctions.
\end{abstract}

cuticular hydrocarbons / Apidae / Euglossa / orchid bee / chemotaxonomy

\section{INTRODUCTION}

The orchid bees (Hymenoptera, Apidae, Euglossini), neotropical, often conspicuously coloured bees, are well known for the males' behaviour of collecting volatiles. They have evolved specialized structures for the manipulation of those chemicals, for example hind tibial pouches and tufts of hair on the middle tibia (Dressler 1982). These structures, together with other morphological characteristics as well as coloration, are used for identification (see Roubik and Hanson 2004). Analyses of the males' perfume composition have provided chemical information for species distinction (Eltz et al.

Corresponding author: T. Pokorny, tamara.pokorny@ruhr-uni-bochum.de Manuscript editor: Klaus Hartfelder
2005; Zimmermann et al. 2009). However, since the perfume is gradually accumulated from the environment, its composition is variable between individuals and may not always allow unambiguous species assignment. Analyses based on molecular markers may also present difficulties, especially when concerning closely related species. In orchid bees base changes in cytochrome c oxidase subunit 1 were uninformative among the sibling species Euglossa viridissima Friese and Euglossa dilemma Bembé \& Eltz (Eltz et al. 2011), while microsatellite markers showed too much overlap in allele sizes to be diagnostic for every single individual bee (Eltz et al. 2008). A similar case of nuclear data yielding ambiguous results has been reported for two closely related species of ants. The species could nevertheless be distinguished based, among others, on cuticular hydrocarbon profiles (Seppä et al. 2011). Considering these points, we aimed to determine whether cuticular lipids, which can be 
used for chemotaxonomic purposes (i.e., are species specific) within various insect families (see Howard 1993; Howard and Blomquist 2005; Bagnères and Wicker-Thomas 2010), might also present a reliable option for orchid bees. To test this, we focused on the sibling species $E$. viridissima and E. dilemma. They are morphologically very similar except for the position and the number of mandibular teeth in males, of which all E. dilemma have three. In $E$. viridissima, the majority of males have two, while, confusing matters, a rare morph $(\sim 10 \%$ of the male population) expresses a third mandibular tooth (Eltz et al. 2011). This had long prevented the recognition of the two distinct species (thus, the rare morph will hence be described as exhibiting an 'obscuring' characteristic). However, since the middle tooth of the rare morph is always slightly dislocated towards the tip of the mandible, it can be distinguished from E. dilemma based on the resulting differences of inter-tooth distances. This finding, combined with analyses of perfume composition and genetic characters, could finally settle the classification (Eltz et al. 2011). In our study we analysed the cuticular lipid profiles of males of both species, including individuals of $E$. viridissima with the obscuring mandibular characteristic, in order to assess their potential for species distinction. As cuticular profiles can differ among populations (Dapporto 2007) or might depend on food or seasonal factors (Liang and Silverman 2000; Liu et al. 2001; Buczkowski et al. 2005; Martin et al. 2012), our samples covered two locations and both seasons, rainy and dry.

\section{METHODS AND MATERIALS}

Bees were captured at chemical baits placed at the locations Tecoh and Chicbul, situated $266 \mathrm{~km}$ apart, on the western side of the Yucatán Peninsula, Mexico. Collection took place in March (dry season) and September (rainy season) of 2010. Per season and location, seven individuals of E. dilemma and $E$. viridissima and, always additionally, an eighth individual of the latter species exhibiting the obscuring mandibular characteristic were captured.
Bees were killed by freezing, and all legs were removed to avoid contamination with perfume substances. The body was then extracted in $500 \mu \mathrm{L}$ of hexane for $1 \mathrm{~min}$. Extracts were analysed using a HP 5890 II gas chromatograph coupled with a HP 5972 mass spectrometer. Injection was splitless onto a DB-5MS column $(30 \mathrm{~m} \times 0.25 \mathrm{~mm} \times 0.25 \mu \mathrm{m})$. The oven was programmed from 60 to $300{ }^{\circ} \mathrm{C}$ at $5{ }^{\circ} \mathrm{C} /$ min. The final temperature was kept constant for 15 min. Components were characterised by their mass spectra and retention indices, and considered being identical in any two samples if both aspects clearly matched. Tentative compound identification was accomplished by comparison with synthetic standards or, when none were available, by mass spectral interpretation and comparison with entries in commercially available mass spectral libraries (Adams 2001 and Wiley 275). Double-bond position for alkenes was evaluated by mass spectral interpretation of dimethyl disulfide (DMDS) derivatives (see Carlson et al. 1989). Integrated ion currents (peak areas) were standardized by total to yield percentage contributions of each compound to an individual profile. Analyses were carried out using all components (all) or subgroups consisting of either only aliphatic hydrocarbons (hc) or solely acetates and alcohols (aa). Intraspecific and interspecific similarity was evaluated by non-metric multidimensional scaling (MDS) and one-way analysis of similarities (ANOSIM). ANOSIM is used to test for compositional differences between sample groups and is based on average ranked values of Bray-Curtis measures of dissimilarity for multivariate data sets (Clarke and Gorley 2006). Resulting $R$ values range from -1 to 1 and are a comparative measure of the degree of separation, rendering them at least as important as their statistical significance. Negative values are rare, resulting from higher dissimilarity within sample groups than between them. $R=0$ indicates that no differences are present between sample groups, while $R=1$ results when groups differ completely. Values in between indicate the degree of differentiation of the groups. Substance contribution to dissimilarity of species was calculated using one-way Bray-Curtis similarity percentage (SIMPER) analyses. All analyses were done with the software Primer v6 (Clarke 1993; Clarke and Gorley 2006). 


\section{RESULTS}

Cuticular extracts contained up to 68 compounds, mainly aliphatic hydrocarbons (on average $59.65 \%$ of total compounds), as well as acetates and alcohols. Seven substances could not be assigned to any of these compound classes. DMDS derivatives allowed the evaluation of double-bond position in alkenes, but not in alkadienes. In all ANOSIM analyses, there was a marginal distinction within species concerning season (all: $R<0.11, E$. dilemma: n.s., E. viridissima: $P<0.05$; hc: $R<0.19, P<$ 0.05 (both species); aa: $R<0.12, E$. dilemma: n.s., E. viridissima: $P<0.05)$. A distinction between the locations from which the extracts had been obtained was only found for aa of $E$. dilemma (all: $R<0.08$, n.s.; hc: $R<0.04$, n.s.; aa: $R<0.16$, E. dilemma: $P<0.01, E$. viridissima: n.s.). The slight seasonal and local differences within each species had no influence on the overall species specificity of the cuticular profiles, which was based predominantly on differences in the relative proportions of compounds, rather than on exclusive compounds, as almost all were present in both species (Figure 1). MDS analyses using the subset of acetates and alcohols did not allow unambiguous species classification owing to a slight overlap of clusters (Figure 2c), while analyses using all components (Figure 2a) or the subset of aliphatic hydrocarbons (Figure 2b) produced distinct, species-specific clusters, clearly placing the individuals with the obscuring mandibular characteristic within $E$. viridissima (ANOSIM differentiation between the two morphs, all: $R=-0.036$, n.s.; hc: $R=$ -0.111 , n.s.; aa: $R=0.197, P<0.05)$. ANOSIM analyses confirmed the MDS results distinguishing between the two species (all: $R=0.87, P<0.01$; hc: $R=0.96, P<0.01$; aa: $R=$ $0.19, P<0.01)$ with the highest $R$ values resulting for the subset of aliphatic hydrocarbons, which made up nearly half of the total number of compounds found in cuticular extracts. In accordance, SIMPER analysis revealed that the dissimilarity between species is mainly due to differing abundances of 9-heptacosene (9-C27:1) and 9-pentacosene (9C25:1), as well as, to a much lesser extent, (11Z)-eicosene-1-yl acetate and (9Z)-eicosene1,20-diyl diacetate. Of these, the average contribution of the first two substances lies over $25 \%$ each to the dissimilarity observed, while the next highest contribution is below $13 \%$. When examining only the data subset of aliphatic hydrocarbons, the average contribution to the dissimilarity of species rises to over $38 \%$ for $9-\mathrm{C} 27: 1$ and to $37 \%$ for $9-\mathrm{C} 25: 1$. A comparison of the relative compound contributions to the cuticular aliphatic hydrocarbon profile clearly shows the differentiation of the two species. Each of the two compounds features prominently in the respective species' hydrocarbon profile with the relative amounts of 9-C27:1 and 9-C25:1 differing by about $30 \%$ between species (Table I, Figure 1). Relative abundances for more than half of the other aliphatic hydrocarbons differed as well (pairwise comparisons, $t$ test with Bonferroni correction; see Table I), though to a much lesser extent.

\section{DISCUSSION}

A low intraspecific differentiation of the cuticular extracts was found between seasons and only once between the two sampled locations. Since the trend of changes was not identical for both species, it seems unlikely that the changes were a response to the dryer and hotter or, respectively, wetter and colder conditions. The differences might instead be due to a differing composition of food resources (nectar- and/or pollen-providing plants) during the dry and the rainy seasons. Diet-related changes of cuticular profiles have previously been reported for ants (Liang and Silverman 2000; Buczkowski et al. 2005). The slight intraspecific disparity of profiles nevertheless had no effect on the overall species specificity. MDS analyses resulted in clear species-specific clusters when using either all substances or aliphatic hydrocarbons. Acetates and alcohols alone were not sufficient for unambiguous species distinction, with ANOSIM analyses 


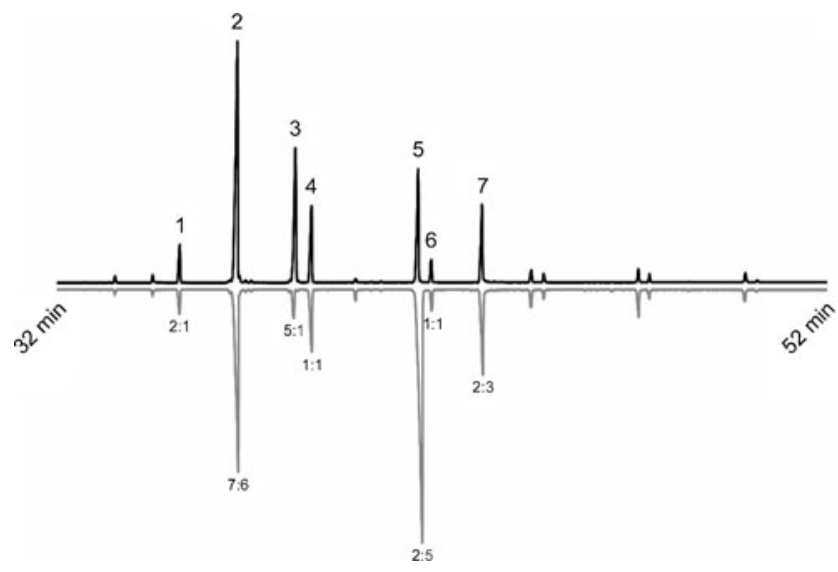

Figure 1. Gas chromatograms of cuticular extracts from E. dilemma (black) and E. viridissima (grey), time frame in which the highest peaks elute (earlier eluting peaks too low to visualise). Compounds with high abundance: 1, tricosane; 2, 11-eicosene-1-yl acetate; 3, 9-pentacosene; 4, pentacosane; 5, 9-heptacosene; 6, heptacosane; 7, 9-eicosene-1,20-diyl diacetate. Average relative amounts (E. dilemma/E. viridissima) listed below the respective peaks.

yielding similar results for the comparisons of the two species and of the two morphs of $E$. viridissima. The seven unidentified substances hardly contributed to interspecific differences. This indicates that the aliphatic hydrocarbons are sufficient for species distinction on their own. Besides, acetates and alcohols, amongst others (11Z)-eicosene-1-yl acetate and (9Z)eicosene-1,20-diyl diacetate, which together made up more than $35 \%$ of the total cuticular profile, can be found in large amounts in the well-developed cephalic labial glands of male bees (Eltz et al. 2007), and it is likely that most of these substances originate from those glands. They could have been extracted from the heads during extraction of the bees' bodies, or they might have been transferred to the cuticula during self-grooming activities in which orchid bees often engage. Of the substances accounting for the dissimilarity between species, the two dominant ones are aliphatic hydrocarbons, strengthening the assumption that the chemical species specificity is largely based on the hydrocarbon profile. The individuals of $E$. viridissima exhibiting the obscuring mandibular characteristic showed no obvious deviation in their cuticular hydrocarbon $(\mathrm{CHC})$ profiles and were assigned to the correct species cluster, thereby further confirming their taxonomic position within $E$. viridissima. Whereas species specificity of $\mathrm{CHC}$ is in many cases a consequence of both differences in the presence and absence of compounds as well as differences in the relative amounts of the compounds (see Howard 1993; Howard and Blomquist 2005; Bagnères and Wicker-Thomas 2010), here the sibling species differed mainly in the relative abundances of two substances. This might be due to their close phylogenetic relationship. It is conceivable that already small mutations affecting the elongation process used during the biosynthesis of hydrocarbons might bring about the interspecifically differing abundances of 9-C27:1 and 9-C25:1. Also, Kather and Martin (2012) argued that recent speciation events would be likely reflected in changes of the $\mathrm{CHC}$ profiles whereas morphological or genetic characters might require a longer time until obvious changes can be detected.

We conclude that $\mathrm{CHC}$ are promising characters for chemical taxonomy in the Euglossini, potentially separating even closely related species, and, if combined with analyses 


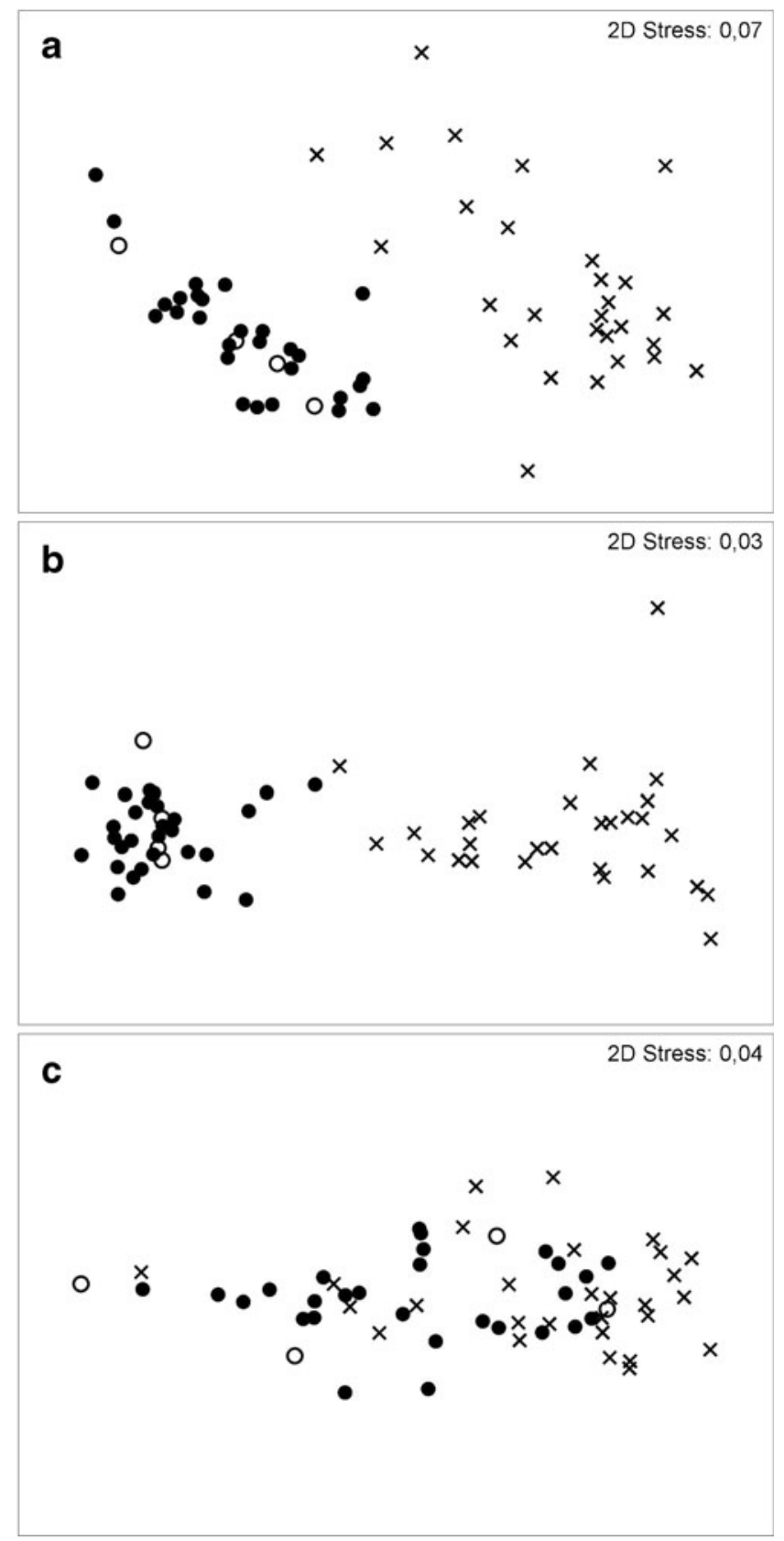

Figure 2. Differences between cuticular profiles of E. dilemma (multiplication signs) and E. viridissima (filled circles) plotted using multidimensional scaling (MDS) based on Bray-Curtis similarity. E. viridissima males exhibiting the obscuring mandibular characteristic (additional third tooth) are depicted by empty circles. Analysed data included (a) all compounds found in extracts, (b) only aliphatic hydrocarbons and (c) only acetates and alcohols. 
Table I. Relative compound contribution (percent) to aliphatic cuticular hydrocarbon profiles. Compound abbreviation: alkanes with chain length $\mathrm{n}, \mathrm{Cn}$; alkenes with chain length $\mathrm{n}$ and position of double bond $\mathrm{x}, \mathrm{x}-$ $\mathrm{Cn}: 1$; alkadienes with chain length $\mathrm{n}, \mathrm{Cn}: 2$. Average values and standard deviation given for $E$. dilemma $(n=$ 28), E. viridissima (normal morph, $n=28$ ) and E. viridissima $\mathrm{f} 3 \mathrm{D}$ (morph exhibiting obscuring feature of three mandibular teeth, $n=4)$. The two morphs of E. viridissima did not differ in their cuticular hydrocarbon profile.

\begin{tabular}{|c|c|c|c|c|}
\hline Compound & RI & E. dilemma & E. viridissima & E. viridissima $\mathrm{f} 3 \mathrm{D}$ \\
\hline $8-\mathrm{C} 17: 1$ & 1,680 & $00.04^{ \pm} 00.07$ & $00.15^{ \pm} 00.18$ & $00.14^{ \pm} 00.18$ \\
\hline $\mathrm{C} 17^{\mathrm{a}}$ & 1,700 & $00.01^{ \pm} 00.02$ & $00.04^{ \pm} 00.04$ & $00.02^{ \pm} 00.05$ \\
\hline C19 & 1,900 & $00.02^{ \pm} 00.03$ & $00.06^{ \pm} 00.05$ & $00.05^{ \pm} 00.06$ \\
\hline $\mathrm{C} 21$ & 2,100 & $00.16^{ \pm} 00.08$ & $00.16^{ \pm} 00.09$ & $00.13^{ \pm} 00.08$ \\
\hline $\mathrm{C} 22^{\mathrm{a}}$ & 2,200 & $00.07^{ \pm} 00.04$ & $00.03^{ \pm} 00.04$ & $00.02^{ \pm} 00.05$ \\
\hline $9-\mathrm{C} 23: 1^{\mathrm{a}}$ & 2,274 & $00.20^{ \pm} 00.13$ & $00.08^{ \pm} 00.11$ & $00.06^{ \pm} 00.11$ \\
\hline $7-C 23: 1^{a}$ & 2,281 & $00.10^{ \pm} 00.10$ & $00.00^{ \pm} 00.00$ & $00.00^{ \pm} 00.00$ \\
\hline $\mathrm{C} 23^{\mathrm{a}}$ & 2,300 & $08.63^{ \pm} 02.63$ & $04.39^{ \pm} 01.25$ & $04.38^{ \pm} 00.50$ \\
\hline 9-C24:1 & 2,374 & $00.76^{ \pm} 00.25$ & $00.53^{ \pm} 00.33$ & $00.77^{ \pm} 00.60$ \\
\hline $\mathrm{C} 24^{\mathrm{a}}$ & 2,400 & $00.63^{ \pm} 00.14$ & $00.50^{ \pm} 00.08$ & $00.55^{ \pm} 00.06$ \\
\hline $\mathrm{C} 25: 2$ & 2,470 & $00.80^{ \pm} 00.44$ & $00.47^{ \pm} 00.39$ & $00.47^{ \pm} 00.22$ \\
\hline $9-\mathrm{C} 25: 1^{\mathrm{a}}$ & 2,474 & $37.50^{ \pm} 07.14$ & $07.43^{ \pm} 03.94$ & $05.73^{ \pm} 01.90$ \\
\hline $7-C 25: 1^{a}$ & 2,482 & $00.84^{ \pm} 00.27$ & $00.34^{ \pm} 00.13$ & $00.28^{ \pm} 00.08$ \\
\hline $\mathrm{C} 25$ & 2,500 & $16.86^{ \pm} 02.65$ & $15.19^{ \pm} 01.38$ & $16.64^{ \pm} 01.85$ \\
\hline $9-\mathrm{C} 26: 1 \& 8-\mathrm{C} 26: 1^{\mathrm{a}}$ & 2,575 & $00.98^{ \pm} 00.28$ & $01.81^{ \pm} 00.32$ & $01.65^{ \pm} 00.26$ \\
\hline $\mathrm{C} 26$ & 2,600 & $00.19^{ \pm} 00.06$ & $00.15^{ \pm} 00.03$ & $00.17^{ \pm} 00.03$ \\
\hline $\mathrm{C} 27: 2^{\mathrm{a}}$ & 2,672 & $00.13^{ \pm} 00.09$ & $00.46^{ \pm} 0.30$ & $00.52^{ \pm} 00.28$ \\
\hline 9-C27: $1^{\mathrm{a}}$ & 2,675 & $19.67^{ \pm} 08.52$ & $50.39^{ \pm} 04.43$ & $49.98^{ \pm} 03.56$ \\
\hline $7-\mathrm{C} 27: 1^{\mathrm{a}}$ & 2,684 & $00.32^{ \pm} 00.13$ & $00.86^{ \pm} 00.19$ & $00.95^{ \pm} 00.11$ \\
\hline $\mathrm{C} 27$ & 2,700 & $05.01^{ \pm} 01.52$ & $04.89^{ \pm} 00.82$ & $05.54^{ \pm} 00.91$ \\
\hline $9-\mathrm{C} 28: 1^{\mathrm{a}}$ & 2,876 & $00.00^{ \pm} 00.02$ & $00.09^{ \pm} 00.05$ & $00.11^{ \pm} 00.06$ \\
\hline $\mathrm{C} 28$ & 2,800 & $00.15^{ \pm} 00.10$ & $00.14^{ \pm} 00.10$ & $00.20^{ \pm} 00.14$ \\
\hline $9-\mathrm{C} 29: 1^{\mathrm{a}}$ & 2,876 & $00.81^{ \pm} 00.51$ & $02.34^{ \pm} 00.66$ & $02.48^{ \pm} 00.69$ \\
\hline $\mathrm{C} 29$ & 2,900 & $01.98^{ \pm} 00.81$ & $02.00^{ \pm} 00.47$ & $02.16^{ \pm} 00.41$ \\
\hline $9-\mathrm{C} 30: 1^{\mathrm{a}}$ & 2,978 & $00.00^{ \pm} 00.01$ & $00.04^{ \pm} 00.04$ & $00.04^{ \pm} 00.05$ \\
\hline $\mathrm{C} 30$ & 3,000 & $00.03^{ \pm} 00.04$ & $00.02^{ \pm} 00.04$ & $00.04^{ \pm} 00.04$ \\
\hline $9-\mathrm{C} 31: 1^{\mathrm{a}}$ & 3,079 & $01.33^{ \pm} 00.78$ & $03.37^{ \pm} 01.06$ & $03.40^{ \pm} 01.19$ \\
\hline $\mathrm{C} 31$ & 3,100 & $01.57^{ \pm} 00.80$ & $01.68^{ \pm} 00.46$ & $01.61^{ \pm} 00.13$ \\
\hline 9-C $32: 1^{a}$ & 3,178 & $00.00^{ \pm} 00.02$ & $00.06^{ \pm} 00.06$ & $00.06^{ \pm} 00.06$ \\
\hline $9-C 33: 1^{\mathrm{a}}$ & 3,278 & $00.76^{ \pm} 00.49$ & $01.82^{ \pm} 00.81$ & $01.48^{ \pm} 00.74$ \\
\hline $\mathrm{C} 33$ & 3,300 & $00.34^{ \pm} 00.25$ & $00.42^{ \pm} 00.18$ & $00.31^{ \pm} 00.02$ \\
\hline
\end{tabular}

$R I$ Kovats retention index for the respective compound

${ }^{a}$ Compounds for which the relative amounts differ significantly between species ( $t$ test with Bonferroni correction)

of perfume composition and genetic approaches, might promote the discovery of yet undistinguished sibling species. CHC might also present a possibility of assigning females to their respective species, which up until now remains problematic in some cases. Whether female CHC profiles exactly resemble the males', or whether CHC might serve as close- 
range recognition cues or as sex pheromones, as could be shown in other insect groups (see Howard and Blomquist 2005; Blomquist and Bagnères 2010), would be an interesting topic of future research.

\section{ACKNOWLEDGMENTS}

Marko Hannibal and Jorge Ramirez Pech helped with sample collection. This work was supported by the Deutscher Akademischer Austausch Dienst PROALMEX programme and the Deutsche Forschungsgemeinschaft (El 249/6). Two anonymous reviewers helped to improve an earlier version of this manuscript.

Les hydrocarbures cuticulaires permettent de distinguer les espèces jumelles cryptiques chez les abeilles à orchidée du genre Euglossa

hydrocarbures cuticulaires / Apidae / Euglossa / chimiosystématique / abeilles à orchidée

Unterscheidung zwischen kryptischen Schwesterarten von Prachtbienen (Euglossa) anhand kutikulärer Kohlenwasserstoffe

kutikuläre Kohlenwasserstoffe / Apidae / Euglossa / Prachtbiene / Chemotaxonomie

\section{REFERENCES}

Adams, R.P. (2001) Identification of essential oil components by gas chromatography/quadrupole mass spectroscopy. Allured Publishing, Carol Stream

Bagnères, A.G., Wicker-Thomas, C. (2010) Chemical taxonomy with hydrocarbons. In: Blomquist, G.J., Bagnères, A.G. (eds.) Insect Hydrocarbons. Biology, Biochemistry and Chemical Ecology, pp. 121-162. Cambridge University Press, Cambridge

Blomquist, G.J., Bagnères, A.G. (2010) Insect hydrocarbons. Biology, biochemistry, and chemical ecology. Cambridge University Press, Cambridge

Buczkowski, G., Kumar, R., Suib, S.L., Silverman, J. (2005) Diet-related modification of cuticular hydrocarbon profiles of the argentine ant, Linepithema humile, diminishes intercolony aggression. J. Chem. Ecol. 31(4), 829-843
Carlson, D.A., Roan, C.-S., Yost, R.A., Hector, J. (1989) Dimethyl disulfide derivatives of long chain alkenes, alkadienes, and alkatrienes for gas chromatography/ mass spectrometry. Anal. Chem. 61, 1564-1571

Clarke, K.R. (1993) Non-parametric multivariate analyses of changes in community structure. Aust. J. Ecol. 18, 117-143

Clarke, K.R., Gorley, R.N. (2006) PRIMER v6: user manual/tutorial. PRIMER-E, Plymouth

Dapporto, L. (2007) Cuticular lipid diversification in Lasiommata megera and Lasiommata paramegaera: the influence of species, sex and population (Lepidoptera: Nymphalidae). Biol. J. Linn. Soc. 91, 703-710

Dressler, R.L. (1982) Biology of the orchid bees (Euglossini). Ann. Rev. Ecol. Syst. 13, 373-394

Eltz, T., Roubik, D.W., Lunau, K. (2005) Experiencedependent choices ensure species-specific fragrance accumulation in male orchid bees. Behav. Ecol. Sociobiol. 59, 149-156

Eltz, T., Zimmermann, Y., Haftmann, J., Twele, R., Francke, W., Quezada-Euan, J.J.G., Lunau, K. (2007) Enfleurage, lipid recycling and the origin of perfume collection in orchid bees. Proc. R. Soc. B 274, 2843-2848

Eltz, T., Zimmermann, Y., Pfeiffer, C., Ramirez-Pech, J., Twele, R., Francke, W., Quezada-Euan, J.J.G., Lunau, K. (2008) An olfactory shift is associated with male perfume differentiation and species divergence in orchid bees. Curr. Biol. 18, 18441848

Eltz, T., Fritzsch, F., Ramirez-Pech, J., Zimmermann, Y., Quezada-Euan, J.J.G., Ramírez, S.R., Bembé, B. (2011) Characterization of the orchid bee Euglossa viridissima (Apidae: Euglossini) and a novel cryptic sibling species, by morphological, chemical, and genetic characters. Zool. J. Linn. Soc. 163, 10641076

Howard, R.W. (1993) Cuticular hydrocarbons and chemical communication. In: Stanley-Samuelson, D.W., Nelson, D.R. (eds.) Insect Lipids: Chemistry, Biochemistry and Biology, pp. 179-226. University of Nebraska Press, Lincoln

Howard, R.W., Blomquist, G.J. (2005) Ecological, behavioural, and biochemical aspects of insect hydrocarbons. Annu. Rev. Entomol. 50, 371393

Kather, R., Martin, S.J. (2012) Cuticular hydrocarbon profiles as a taxonomic tool: advantages, limitations and technical aspects. Physiol. Entomol. 37, 25-32

Liang, D., Silverman, J. (2000) "You are what you eat": diet modifies cuticular hydrocarbons and nestmate recognition in the Argentine ant, Linepithema humile. Naturwissenschaften 87, 412-416

Liu, Z.B., Bagnères, A.G., Yamane, S., Wang, Q.C., Kojima, J. (2001) Intra-colony, inter-colony and seasonal variations of cuticular hydrocarbon profiles 
in Formica japonica (Hymenoptera, Formicidae). Insect. Soc. 48, 342-346

Martin, S.J., Shemilt, S., Drijfhout, F.P. (2012) Effect of time on colony odour stability in the ant Formica exsecta. Naturwissenschaften 99, 327-331

Roubik, D.W., Hanson, P.E. (2004) Orchid bees of tropical America. Instituto Nacional de Biodiversidad (INBio), Heredia
Seppä, P., Helanterä, H., Trontti, K., Punttila, P., Chernenko, A., Martin, S.J., Sundström, L. (2011) The many ways to delimit species: hairs, genes and surface chemistry. Myrmecol. News 15, 31-41

Zimmermann, Y., Ramírez, S.R., Eltz, T. (2009) Chemical niche differentiation among sympatric species of orchid bees. Ecology 90(11), 29943008 